\title{
ADDRESSING LEARNER CULTURAL DIVERSITY IN MOOC DESIGN AND DELIVERY: STRATEGIES AND PRACTICES OF EXPERTS
}

\author{
Dr. Meina ZHU \\ ORCID: 0000-0002-5901-9924 \\ Learning Design and Technology, Wayne State University \\ Detroit, USA \\ Najia SABIR \\ ORCID: 0000-0002-2189-5136 \\ Instructional Systems Technology Department, Indiana University \\ Bloomington, USA \\ Dr. Curtis J. BONK \\ ORCID: 0000-0002-6365-9502 \\ Instructional Systems Technology Department, Indiana University \\ Bloomington, USA \\ Annisa SARI \\ ORCID: 0000-0001-7233-1683 \\ Accounting Education Department, Yogyakarta State University \\ Yogyakarta, INDONESIA \\ Dr. Shuya XU \\ ORCID: 0000-0003-1254-8332 \\ TechSoup Learning, TechSoup \\ San Francisco, USA \\ Dr. Minkyoung KIM \\ ORCID: 0000-0002-6394-1946 \\ Instructional Design and Technology, University of West Florida \\ Pensacola, USA
}

Received: 07/09/2020 Accepted: 05/11/2020

\begin{abstract}
This mixed-methods study investigates the design and instructional practices of massive open online courses (MOOCs) instructors within the learning environment to address the cultural diversity and learner personalization needs. Leveraging a grounded theory approach, the researchers analyzed two rounds of email interviews ( $\mathrm{n} 1=25 ; \mathrm{n} 2=19)$ with $\mathrm{MOOC}$ and open education leaders about cultural sensitivity and personalization in MOOCs. Those interviews led to the formation of a 30-item online questionnaire completed by 152 MOOC instructors. While many of the MOOC instructors within the sample did not fully grasp the complex issues of cultural diversity, most made attempts to modify their instructional practices to accommodate cultural variances. To address cultural and linguistic differences, instructors added subtitles to video content and offered transcripts for video or audio content. Additionally, instructors were careful with language use and hand gestures, used simplified language, slowed their pace of speech, made the course content easy to navigate, limited text by leveraging (multi)media, and encouraged learners to translate and localize content for their peers. Furthermore, many instructors favored collaborative, small group learning; however, instructors could not agree on best practices to establish these groups. Implications and future directions for MOOC instructors and instructional designers are offered.
\end{abstract}

Keywords: MOOCs, open education, instructional practices, cultural sensitivity, cultural diversity, MOOC Instructors. 


\section{INTRODUCTION}

Open online courses, specifically massive open online courses (MOOCs), have become increasingly popular, allowing for thousands of individuals within a course to engage simultaneously learning (Cormier \& Siemens, 2010) while also providing millions of individuals around the globe access to thousands of MOOCs, and their associated free and open educational resources (Shah, 2015, 2016). The latest data from Class Central showed that in 2018, over 101 million learners enrolled in more than 11,400 MOOCs (Shah, 2019). This report also indicated that these MOOCs were provided by more than 900 different institutions around the world (Shah, 2019). While earlier MOOC research from Jordan (2014) found that the average MOOC enrolled approximately 43,000 learners, as MOOC offerings have increased, the average enrollment has decreased to approximately 8,000 (Chuang \& Ho, 2016).

Naturally, such numbers have attracted much attention from researchers, practitioners, and the news media as well as government agencies, institutions of higher education, entrepreneurs, and venture capitalists (Riel \& Lawless, 2017). MOOCs are now hosted on myriad platforms, including edX, Udacity, Udemy, FutureLearn, and Coursera (Pappano, 2012). As the number of MOOCs offered continues to grow, instructors are challenged to accommodate for the growing socio-cultural and linguistic diversity of learners. Despite mounting cross-cultural challenges due to MOOC expansion, few empirical studies examine how MOOCs and MOOC instructors address diversity issues. Many research studies focus on the learner experience in MOOCs (Zhu, Sari, \& Lee, 2018), such as learner's behavior (Kahan, Soffer, \& Nachmias, 2017), dropout rate (Halawa, Greene, \& Mitchell, 2014; Kizilcec, Perez-Sanagustin, \& Maldonado, 2017), and motivation of learners (Milligan \& Littlejohn, 2017).

As MOOCs and other forms of distance education enrollments soar, understanding and adopting for learner preferences, cultural and linguistic differences, and assorted other variables become crucial (Speece, 2012). Liu et al. (2016) found that learners' performance in MOOCs was influenced by cultural diversities. Paying attention to the learners' cultural and linguistic attributes will enhance the access and success of learning through better online presence, perceptions, and performance (Wang, 2007). In turn, this study seeks to understand how MOOC instructors are personalizing MOOCs to meet the needs of culturally, linguistically, and nationally diverse learners. More specifically, this mixed-method study is driven by two primary research questions:

1. To what degree do MOOC instructors perceive the learning environments that they have designed as accommodating learner and cultural diversity?

2. What are the instructional practices that MOOC instructors rely upon to address diverse cultural backgrounds? For instance, what cultural sensitivity and personalization practices do MOOC instructors utilize to enrich the virtual classroom experience of its diverse participants?

Research Question \#1 relates to the design of MOOCs for cultural sensitivity and diversity practices. Research Question \#2 concerns the actual delivery of MOOCs in the form of adaptive instructional practices.

\section{THE EVOLUTION OF MOOCS}

Since their introduction in 2008 (Cormier \& Siemens, 2010), MOOCs have become mainstream, drawing throngs of self-directed, highly motivated adult learners. A key part of this expansion was salient in the news in 2011, when Stanford Professors Sebastin Thrun and Peter Novig opened their online artificial intelligence class to anyone in the world with Internet access, resulting in over 160,000 adult learners from 190 different countries (Dekena, 2012; Markoff, 2011; Rodriguez, 2012). Researchers have revealed some essential factors in drawing such large enrollments, including opportunities to achieve personal learning goals, develop new skills, and expand one's professional networks (McAuley, Stewart, Siemens, \& Cormier, 2010; Siemens, 2012a). 
Often MOOCs are held asynchronously, with some optional, scheduled meetings, allowing learners the flexibility to manage not only what they learn, but also how they learn (Kim \& Chung, 2015; Severance, 2015). This element of flexibility is vital for MOOC learners since it reduces the perceived learning barriers; if they have a somewhat stable Internet connection, they can enroll in nearly any open online course that fancies them (Bonk et al., 2018; Jordan, 2014). The openness and flexibility of a MOOC has resulted in such open courses not only becoming common in academia but also being utilized by international organizations such as the Commonwealth of Learning (Venkataraman \& Kanwar, 2015), the World Bank (Jagannathan, 2015), the United Nations, and OECD. They can also directly address various regional and national government initiatives (Alony, Kaye, \& Lambert, 2015; Boga \& McGreal, 2014; Czerniewicz, Deacon, Small, \& Walji, 2014; Miller \& Jay, 2015; Warugaba, Naughton, Gauthier, Muhirwa, \& Amoroso, 2016). As MOOCs become more accepted and embraced as reputable, and perhaps even essential, ways to learn new skills, the backgrounds, experiences, and needs of MOOC learners multiply.

What has been apparent since inception is that MOOCs and other forms of open education tend to draw self-directed learners. Such intrinsically motivated adults seek to achieve personal learning goals, develop new skills and competencies, and enjoy opportunities to network and interact with others (McAuley et al., 2010; Siemens, 2012a). Unfortunately, the gap between the high expectations of meeting individual learning goals and the open-ended or less guided nature of MOOCs often results in MOOC participants struggling to complete them (Belanger \& Thornton, 2013; Christensen, Steinmetz, Alcorn, Bennett, \& Woods, 2013; MOOC @ Edinburgh 2013 - Report \#1, 2013). In fact, Mackness, Mak, and Williams (2010) claimed that MOOCs are a paradox; while designed for independent learning, they noted that learners frequently rely on peer support to complete the MOOC. McAuley et al. (2010) called for instructors to reevaluate what skills learners need prior to enrolling in the MOOC as well as what specific types of skills necessitate more scaffolding. Other researchers have called for instructors to evaluate if linguistic and technical skills pose difficulties for MOOC participants (e.g., Fini, 2009; Schulze, 2014). Suffice to say, more research on the design of MOOCs is warranted (McAuley et al., 2010; Ostashewski \& Reid, 2012); particularly, design that addresses the diverse cultural backgrounds (Nkuyubwatsi, 2014; Wang, 2007).

As the use of MOOCs has expanded, MOOC leaders and researchers like Siemens (2012b) have increasingly called for instructors to consider their target learners. Meanwhile, Preece, Rogers, and Helen (2007) stated that designing courses that are culturally sensitive can foster positive and effective learner experiences. As distance education enrollment rises, it is pivotal to understand and take into account learner preferences, culture, and style (Speece, 2012). Therefore, the consideration of cultural differences and accommodation of learners with different backgrounds is becoming essential to the design of high-quality MOOCs. Additionally, Gunawardena's (2020) review of online learning white papers and reports found that, by 2030, university instruction in Europe is projected to be "more flexible and provide different learning pathways recognizing the diversity of the student population" (p. 5). Despite such needs, research on the instructional design practices related to cultural diversity in online learning is too limited (Jung \& Gunawardena, 2014; Rogers, Graham, \& Reeves, 2007; Swierczek \& Bechter, 2010; Wang \& Reeves, 2007).

\section{THEORETICAL FRAMEWORK}

Subramony (2004) argues that a lack of attention to cultural diversity in distance education design results in the alienation of adult learners. Culture impacts distance education from two fronts: design and use (Seufert, 2002). MOOCs are often designed and developed in a specific cultural context; however, like most distance education models, what is successful in one cultural context may not carry over to another (Watson, Ho, \& Raman, 1994). In response, Edmundson (2005), Henderson (1996), and Reeves and Reeves (1997) propose a multidimensional approach to address cultural issues in distance education courses.

The notion of 'culture' has been used in common language since the 18th Century (Tylor, 1871); however, there does not seem to be a universally accepted definition. For the purposes of this study, "culture" is a collection of fundamental values and patterns of acting, feeling, and thinking (Ford \& Kotze, 2005), which influence how people communicate, with or without technology. This research study leverages Hofstede and Hofstede's (2005) definition of culture as the "collective programming of the mind that distinguishes the members of one group or category of people from others" (p.4). This complex notion of culture examines 
patterns of beliefs, systems of knowledge, and behaviors. The authors use the analogy of an onion to explain the complexities of culture that include attitude, goals, symbols, practices, and values. While Hofstede's (2001) model is based on national archetypes, it is considered seminal in its relation to many multicultural distance learning environment studies (e.g., Bentley, Vawn-Tinney, \& Chia, 2005; Kondratova, Goldfarb, Gervais, \& Fournier, 2005; Morse, 2003; Renner, Laumer, \& Weitzel, 2015; Rogers et al., 2007; Shishah \& FitzGerald, 2016; Sieffert, 2006; Swierczek \& Bechter, 2010). Given that individual learner's learning preferences may vary across different cultures and/or nations (Fail, 2011; Hofstede, 1983, 1986), it is important to consider cultural diversity in online course design because courses are often developed based on instructors' personal values, preferences, expectations, and experiences (Ahn, Yoon, \& Cha, 2015; Speece, 2012).

Hall's (1976) schema classifies culture into high or low contexts, based on the amount of information a learner expresses or communicates. Individual learners in face-to-face (f2f) learning environments rely mostly on verbal cues to communicate. Communication in high-context cultures becomes challenging due to the lack of $\mathrm{f} 2 \mathrm{f}$ contact in distance education environments where participants rely mostly on the written word (Gobbo, Nieckoski, Rodman, \& Sheppard, 2004; Speece, 2012). As an example of such cultural differences, in one study of learner interactions in solving online case problems via asynchronous conferencing across several cultures, Finnish learners were more reflective and theoretical, Korean learners were more social and contextually driven, and American learners were more action oriented and pragmatic in seeking results (Kim $\&$ Bonk, 2002). Other researchers also explored strategies to create a culturally inclusive online learning environment through developing a learning community, negotiating identity, power, and authority, engaging in authentic inquiry-based learning, supporting collaboration and navigating interactions in an additional language (Gunawardena, 2020).

While MOOCs often incorporate video lectures from instructors, the lack of intimacy in online environments nevertheless presents serious problems (Hannon \& D’Netto, 2007; Morse, 2003). With participants from nearly 200 countries in many MOOCs (Breslow et al., 2013; Ebben \& Murphy, 2014), such intimacy is made even more difficult. In fact, Sandeen (2013) stated that on average, $60 \%$ of the learners in MOOCs are not from the U.S. This raises a growing concern; namely, if instructors and learners lack shared understandings, there is a greater probability of misunderstandings occurring due to language barriers and communication method differences (Callaway, Matthew, \& Felvegi, 2014). Past research has shown that different cultures have different communication patterns (Hofstede, 1986; McLoughlin, 2006).

Gunawardena, Frechette, and Layne (2019) define culture as a "collection of shared perceptions of the world and our place in it" (p. 3). Gunawardena et al. (2019) describe four levels of cultural inclusivity when designing education for global learners. At Level 1, MOOCs cannot directly address cultural variances, but indirectly take on the values, norms, and biases of the instructor/curriculum designer. At Level 2, they allow for the explicit design and inclusion for a specific culture. Next, at Level 3, MOOCs can accommodate different, specific cultural contexts. Finally, at Level 4, they allow for instruction to be created with multicultural learning experiences.

When cultural issues and circumstances are not addressed while designing education, it might lead to misunderstanding (Callaway et al., 2014). There are various ways to address cultural issues. For instance, the course might use a common language like English, but encourage subtitling and transcripts. In addition, in actively building cultural awareness and sensitivity among the learners, the course might be designed to be considerate when using symbols, provide use easy-to-digest examples, take into account time differences among participants, and engage in role modeling (Wendler \& Struthers, 2002; Yousef, Chatti, Schroeder, \& Wosnitza, 2014).

While there is growing literature on online cultural sensitivity, there remains limited discussion related to MOOC design for culturally diverse participants (Teras, 2013; Wang \& Reeves, 2007). Further complicating efforts to design and deliver MOOCs that are culturally sensitive and more personalized, there are few empirical studies representing MOOC instructors' voice in discussing how the learning environment is adapted for learner needs. Much of the MOOC research fixates on learner perspectives (e.g., Paquette, Mariño, Rogozan, \& Leonard, 2015) or present metaliterature reviews which suggest "implementing personalization and adaption in MOOCs in order to improve users' engagements, hence reduc[ing] MOOC's drop-out rate problem" (Sunar, Abdullah, White, \& Davis, 2016, p. 8). 
Kop (2011) argues that instructors are one of the five core success elements (i.e., instructors, learners, topic, materials, and context) in MOOCs. However, as Veletsianos and Shepherdson (2016) and Zhu et al. (2018) reveal, few studies leverage instructor perspectives to better understand such personalization and cultural sensitivity (Veletsianos \& Shepherdson, 2016). In response, this study examined the various ways MOOC instructors design and implement their courses to meet the needs of learners with different cultural and linguistic backgrounds.

\section{METHODS}

This mixed-methods (Creswell \& Plano-Clark, 2017) study analyzes data drawn from: (1) email interviews $(\mathrm{n}=25)$ with MOOCs and open online education experts related to cultural sensitivity and diversity in MOOCs; (2) additional follow-up email interviews ( $\mathrm{n}=19)$ with the same sample, but varying protocols, related to the personalization of MOOCs; and (3) online questionnaire responses from MOOC instructors $(\mathrm{n}=152)$ targeting cultural sensitivity and personalization in MOOCs. Whereas most of the findings related to MOOC personalization practices were reported elsewhere (Bonk et al., 2018), this study was primarily concerned with issues of cultural sensitivity and diversity in the design and delivery of MOOCs.

\section{Expert Interviews}

To understand more about how cultural diversity is addressed, an email was sent in October 2015 to roughly 30 international experts in the field of MOOCs and open education. Each of these experts had contributed a chapter to a book on MOOCs and open education which had been published earlier that year.

In the email, it was prefaced that a factor often overlooked in the field of open education and MOOCs is cultural sensitivity. The goal was to better understand what they deemed best practices for designing and delivering MOOCs in ways that are culturally inclusive and sensitive. The experts were given examples such as being cognizant that images of certain hand gestures or body movements may offend people or not be part of societal norms.

The email then asked these experts to use their expertise and extensive experience related to MOOCs and other forms of open education to make suggestions for the types of cultural accommodations that might be made in MOOCs that are intended for a global audience. As part of this response, they were asked about the guidelines that existed, if any, related to adjusting multimedia and other MOOC components to make them more culturally sensitive; especially as it pertained to their particular culture or region of the world. Practical advice was especially encouraged.

Replies with insights, experiences, and suggestions related to cultural diversity were received from 25 of these experts. Following that, email interviews with 19 experts about the personalization of MOOCs were conducted. A thematic analysis was used to catalogue, summarize, and analyze the interview scripts into "emerging themes [that] become categories for analysis" (Fereday \& Muir-Cochrane, 2006, p. 4). These expert participants were MOOC instructors, course designers, and administrators from universities, institutions, and organizations around the world such as the World Bank Institute, University of Cape Town, Open University of Japan, University of Edinburgh, Future Learn, African Virtual University, University of Michigan, Georgia Tech University, University of the Philippines Open University, Stanford University, ALISON, MERLOT, University of Tasmania, Commonwealth of Learning (COL), and Open University of the Netherlands.

\section{Web-based Survey}

Analysis of the email interviews crystallized points of inquiry (Bogner, Littig, \& Menz, 2009) regarding cultural diversity and personalization in MOOCs and helped to reduce uncertainty when building the online questionnaire (Rappert, 1999). The questionnaire consisted of 30 items and incorporated 25 closed questions and five open-ended items related primarily to MOOC personalization and cultural diversity issues and adaptations. The questionnaire was designed and created via SurveyMonkey, an online survey tool. 
A large database of over 1,000 MOOC instructors and designers was mined from online course platforms (e.g., Class Central, MOOC list, Coursera, edX, and FutureLearn) and cross referenced against proprietary platforms (e.g., Blackboard and Canvas). Instructors were located in more than two dozen countries around the world, including Australia, Belgium, Canada, China, Germany, Ireland, Japan, Korea, Mexico, the Netherlands, Norway, Russia, Singapore, Switzerland, the U.K., and the United States. These instructors taught different subjects such as business and management, medicine, education, and computer science.

In vivo coding and thematic analysis were applied to the open-ended questionnaire responses, identifying MOOC instructional design practices used to personalize the MOOC learning environment via course resources and technological tools. Constant comparison was used to analyze all qualitative data and responses (Glaser \& Strauss, 2009); in effect, iterations of data analysis occurred as new data sources were collected across the various stages of research. Grounded theory informed the methodology, enabling complex, multifaceted dialogs without the constraint of a predefined framework. Data collection and later analysis stages were built off the prior stages, grounding them in the real-world experiences of practitioners (Glaser \& Strauss, 2009; Goulding, 2002).

\section{QUANTITATIVE DATA ANALYSIS RESULTS}

\section{Instructor Experience and Approach}

The survey yielded 152 responses or about a $15 \%$ response rate which was more than adequate (Cho \& LaRose, 1999). The largest percent came from the medical field, followed in order by education, social science, business, computer science, natural science, climate science, data science, art, engineering, mathematics, history, astronomy, and philosophy. While most instructors had only taught one MOOC at the time of the survey, one in four of these instructors had already taught three or more MOOCs. Slightly more than half had never completed a MOOC as a learner in the past.

We also asked about prior experience teaching online or blended. As shown in Figure 1, the online and blended teaching backgrounds of the MOOC instructors were not that extensive. In fact, the previous experience of half of them was on the low side. At the same time, about $28 \%$ indicated that they had much experience teaching online prior to teaching a MOOC. The overall average experience teaching online or blended for the survey respondents was 4.55 on a scale of 1 (low) to 10 (high); however, there was much variability $(\mathrm{SD}=3.5)$. Given the modest experience teaching online, it would be expected that most of these instructors would rely on vendor provided tools and structures, rather than personally designed tools. They would also be expected to use less risky teaching methods compared to those with more extensive online teaching backgrounds.

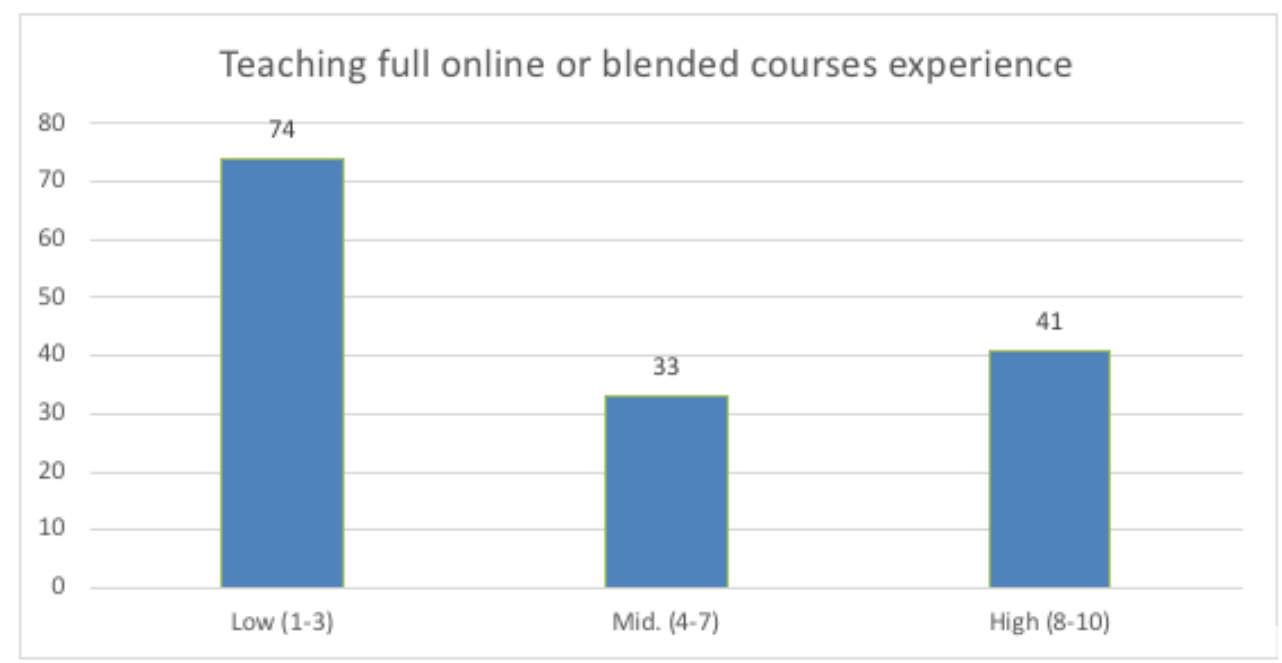

Figure 1. Instructor Experience Teaching Online/Blended Courses prior to Teaching their Recent MOOC

Note: on a scale of 1 (low) to 10 (high)] ( $\mathrm{n}=148)$ 
Despite the lower than expected online learning backgrounds of these instructors, most of them indicated that they were heavily involved in the design of the course content of their MOOC; with an average rating of nearly 9 on a scale of 1 (low) to 10 (high). Therefore, they did have opportunities to specifically address the diverse needs and backgrounds of the learners in their MOOC(s). Furthermore, as reported elsewhere (Bonk et al., 2018), these instructors were hopeful to learn additional ways to better personalize the design of the instruction in their next MOOC.

Naturally, the size of MOOC enrollments might influence the degree to which instructors can personalize their courses and address diverse learner backgrounds, needs, specific situations, and experiences, including cultural, educational, technological, linguistic, and other factors. The data showed that most of these instructors $(71.3 \%)$ were teaching courses with under 25,000 participants and nearly half $(47.3 \%)$ were MOOCs of under 10,000 participants. Only 6\% MOOCs taught by respondents had more than 100,000 participants. While MOOC size was markedly smaller than previously reported by Jordan (2013,2014), these still could be considered enormous courses in size and scope (Chuang \& Ho, 2014), making instructional attempts to address diverse learner needs an extremely daunting task.

As we document elsewhere in a parallel study of instructor personalization of MOOCs (Bonk et al., 2018), more than $85 \%$ of these instructors reported a high degree of involvement in the design of the course content for their most recent MOOC. Unfortunately, that earlier report also noted that just over one-third of these instructors felt that they placed extensive effort on meeting individual learner needs when designing their courses and even less (i.e., 28.5\%) when delivering their MOOCs (Bonk et al., 2018). Importantly, however, the findings of that study indicated that MOOC instructors wanted additional professional development on how to attempt to make their MOOCs more personally engaging.

\section{Instructional Strategies and Tools}

Another common problem encountered by MOOC instructors is the range of learner prior content knowledge and self-confidence. As identified by Fini (2009), Mackness et al. (2010), McAuley et al. (2010), and Schulze (2014), MOOC instructors need to account for learner diversity in linguistic, technical, and content competency throughout the course. Table 1 represents the various ways that the respondents addressed varying participant competencies and needs. Again, discussion forums are the primary mechanism utilized ( $\mathrm{n}=115 ; 81.0 \%$ of respondents), followed by embedding supplemental course materials (e.g., readings, animations and simulations, job aids, news, videos, maps, etc.) ( $\mathrm{n}=111 ; 78.2 \%)$, and the posting of timely course announcements and emails $(\mathrm{n}=90 ; 63.4 \%)$. Items employed less often yet still of importance included the recording of videos and tutorials $(\mathrm{n}=58 ; 40.8 \%)$, emphasizing project-based forms of learning over exams $(\mathrm{n}=49 ; 34.5 \%)$, utilizing preexisting online videos like TED Talks and Lynda.com $(\mathrm{n}=46$; $32.4 \%)$, and holding synchronous lectures, meetings, and events $(\mathrm{n}=34 ; 23.9 \%)$. Somewhat less popular were establishing study groups $(\mathrm{n}=27 ; 19.0 \%)$, incorporating learner reflection journals or blogs $(\mathrm{n}=23$; $16.2 \%)$, scheduling virtual office hours or meetings $(n=20 ; 14.1 \%)$, and offering opportunities for face-toface meetups $(\mathrm{n}=10 ; 7.0 \%)$. Of course, the tools to address the knowledge gaps and deficiencies of MOOC participants will continue to evolve and change in the coming years. 
Table 1. Instructional Practices of MOOC Instructors to Address the Variety of Learner Competencies and Needs $(\mathrm{n}=142)$

\begin{tabular}{lll}
\hline Items & $\begin{array}{l}\text { Response } \\
\text { percent }\end{array}$ & $\begin{array}{l}\text { Response } \\
\text { count }\end{array}$ \\
\hline Establish learner-based discussion forums & $81.0 \%$ & 115 \\
Embed supplementary course materials & $78.2 \%$ & 111 \\
Post timely course announcements and emails & $63.4 \%$ & 90 \\
Record video tutorials or walkthroughs & $40.8 \%$ & 58 \\
Emphasize project-based learning over exams & $34.5 \%$ & 49 \\
Using preexisting online videos (e.g., Lynda.com, TED talks, YouTube, etc.) & $32.4 \%$ & 46 \\
Other & $26.1 \%$ & 37 \\
Hold synchronous lectures, meetings, and events (e.g., Skype, Google Hangouts, Zoom & $23.9 \%$ & 34 \\
etc.) & $19.0 \%$ & 27 \\
Establish study groups & $16.2 \%$ & 23 \\
Establish learner reflection journals or blogs & $14.1 \%$ & 20 \\
Schedule virtual office hours and meetings & $7.0 \%$ & 10 \\
Offer face-to-face meet-up opportunities & & \\
\hline
\end{tabular}

As shown in Table 1, in this fast-changing age of digitally enhanced learning, there are numerous instructional practices and technology tools and resources from which to attempt to address the various competencies and needs of MOOC participants. Accordingly, we asked the respondents how they or their teaching assistants and moderators provided just-in-time support, feedback, and individualized learner attention. Several of the survey respondents noted that they constantly monitor learner performance in the discussion forums and address pressing needs and any perceived learner struggles with discussion forums and Twitter posts. Some others relied on weekly updates, course announcements, or virtual office hours to respond to the most frequently asked questions. As one of them noted, "Constant, constant, constant attention to discussion forums." MOOC instructors also focused on fostering collaboration and a sense of learning community.

One MOOC instructor mentioned how they apportioned the workload among many instructors and teaching assistants and moderated different sections or forums. Others noted that a team of instructors delivered content from their respective areas of expertise and monitor forums and activities related to it. They also apportioned their time so that different people would be online at different times to respond to learner needs. And they let the learners know the specific dates and times that they would be online to discuss issues and answer questions in a synchronous or live fashion. And that was not all. In addition to all this support from the academics, one MOOC instructor stated that, "we also had resident entrepreneurs and business experts (6) who were asked to be online over certain dates/times to provide the 'practical' view. Finally, we also have a central 'digital learning team' who supports all University MOOCs. Their team members were also assigned various dates to moderate and try to add comments, monitor any issues, etc."

\section{Cultural Diversity}

Addressing cultural diversity involves providing participants with options. As revealed in a parallel study (Bonk et al., 2018), these MOOC instructors typically offered optional readings and their course structures allowed the learners to decide about incentives for completion of the MOOC (e.g., certificates, badges, or course credit). Options on assignments or using multimedia to explain difficult concepts were less frequently offered (see Table 2). Only about one-third of these MOOCs allowed learners to generate or contribute content or discuss and negotiate ideas about the course content. Even fewer permitted learners to select their own learning pathways. 
Table 2. Items Instructors Provided in their Most Recent MOOC ( $\mathrm{n}=126)$

\begin{tabular}{lll}
\hline Items the current MOOC covered & Percent & Count \\
\hline Optional readings, videos, or other materials & $74.6 \%$ & 94 \\
Learner selected incentives (e.g., certificates, badges, course credit, etc., options) & $64.29 \%$ & 81 \\
Options with course tasks and assignments & $38.10 \%$ & 48 \\
Learner discussion and negotiation of content & $36.51 \%$ & 46 \\
Two or more media elements to learn the same content & $31.75 \%$ & 40 \\
Learner determined or contributed content & $30.16 \%$ & 38 \\
Learner selected learning pathways (i.e., different routes to learn the same content) & $19.05 \%$ & 24 \\
Learner portfolios of course accomplishments & $16.67 \%$ & 21 \\
Choice in team or collaborative partners (i.e., self-formed teams) & $12.70 \%$ & 16 \\
\hline
\end{tabular}

One means to address the diversity in a MOOC is to allow participants to display their learning in individually preferred or different ways. Again, choice in task or learning activity can be interpreted as being sensitive to people from different cultures and educational backgrounds. However, as illuminated in Figure 2 below, the MOOCs of half of the instructors surveyed did not allow any way for learners to present or share their work with others in the MOOC. In those that did, MOOC participants more often shared their work through social media $(n=33 ; 25.4 \%)$, online sharing exchanges or portals $(n=28 ; 21.5 \%)$, and online galleries $(n=19$; $14.6 \%)$. Not as prevalent were learner blogs $(\mathrm{n}=15 ; 11.5 \%)$, e-portfolio systems $(\mathrm{n}=13 ; 10.0 \%)$, posting one's work to the learning management system $(n=11 ; 8.5 \%)$, or class presentations $(n=6 ; 4.6 \%)$. Clearly, a typical MOOC is not set up to share or showcase one's learning with other participants and stakeholders.

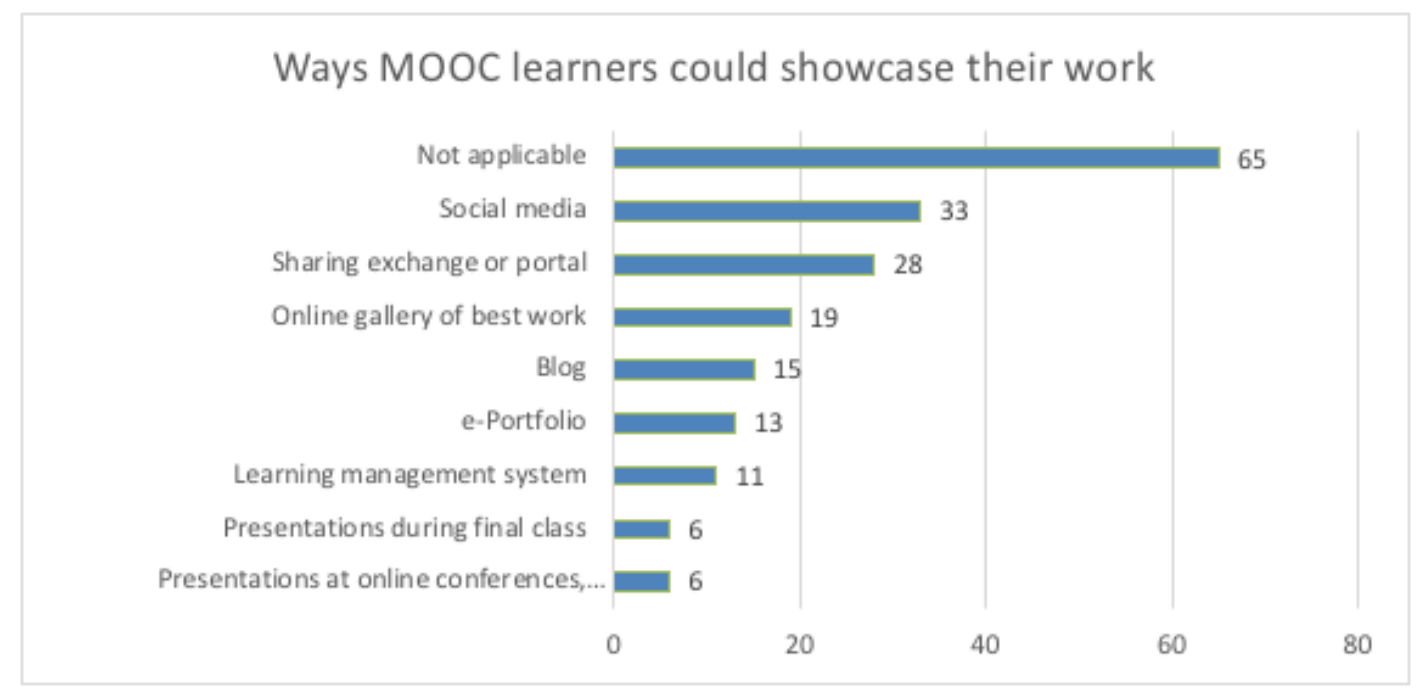

Figure 2. Methods by Which MOOC Learners Could Showcase their Work [Note: on a scale of 1 (low) to 10 (high)] $(\mathrm{n}=130)$

The above tables and figures provide some insight into the size, content, and resources of MOOCs that all might be related to the ability of instructors to address cultural and linguistic diversity. Importantly, two questions specifically were focused on cultural and linguistic adaptations. When asked, on a scale of 1 (low) to 10 (high), how much effort was placed on addressing the needs of individuals from different cultural backgrounds and languages in their most recent MOOC, these instructors put forth modest effort, but, once again, there was much variability $(\mathrm{M}=5.37$; $\mathrm{SD}=2.87)$. Whereas $43(30.5 \%)$ of them put forth high effort, another 45 (31.9\%) respondents put forth low effort; the remaining 53 (37.6\%) MOOC instructors felt that they gave medium effort. In effect, as shown in Figure 3, MOOC instructors were quite varied in their commitment to addressing diverse learner needs. 


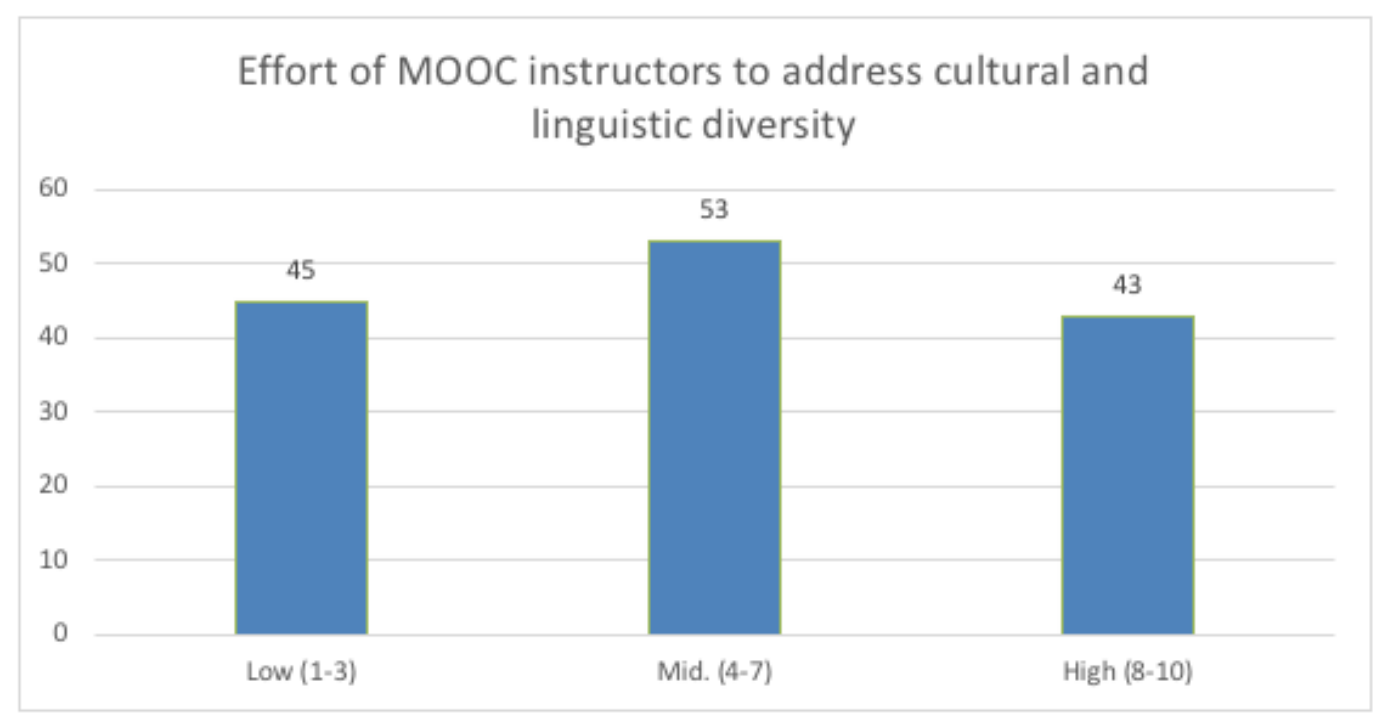

Figure 3. The Perceived Effort of MOOC Instructors in Addressing Cultural and Linguistic Diversity

Note: on a scale of 1 (low) to 10 (high)] $(\mathrm{n}=141)$

Given the modest effort that MOOC instructors placed addressing those participants from different cultural and linguistic backgrounds, it was vital to probe further into the strategies that they implemented. Figure 4 breaks down the order in which MOOC instructors designed their MOOCs to be suitable for learners from different cultures and/or linguistic backgrounds. At the top of the strategies to address cultural diversity was offering transcripts of video and audio contents $(\mathrm{n}=88 ; 66.2 \%)$ and adding subtitles to video content that was provided in the course $(\mathrm{n}=85 ; 63.9 \%)$. The third most common strategy was for MOOC instructors to be careful with the language that they used and any hand gestures $(n=69 ; 51.9 \%)$. Among the other somewhat common techniques included that instructors simplify the language used ( $n=56 ; 42.1 \%)$, slow down their rate of speech $(\mathrm{n}=49 ; 36.8 \%)$, and simplify the course design and make it easier for learners to navigate it $(\mathrm{n}=36 ; 27.1 \%)$. Nearly one in five indicated that they would limit text and rely more on pictures. Slightly less selected that they would encourage participants to translate and localize the content for others $(\mathrm{n}=24 ; 18.1 \%)$. However, only $15(11.3 \%)$ of the respondents designed their courses with parallel translations to other languages.

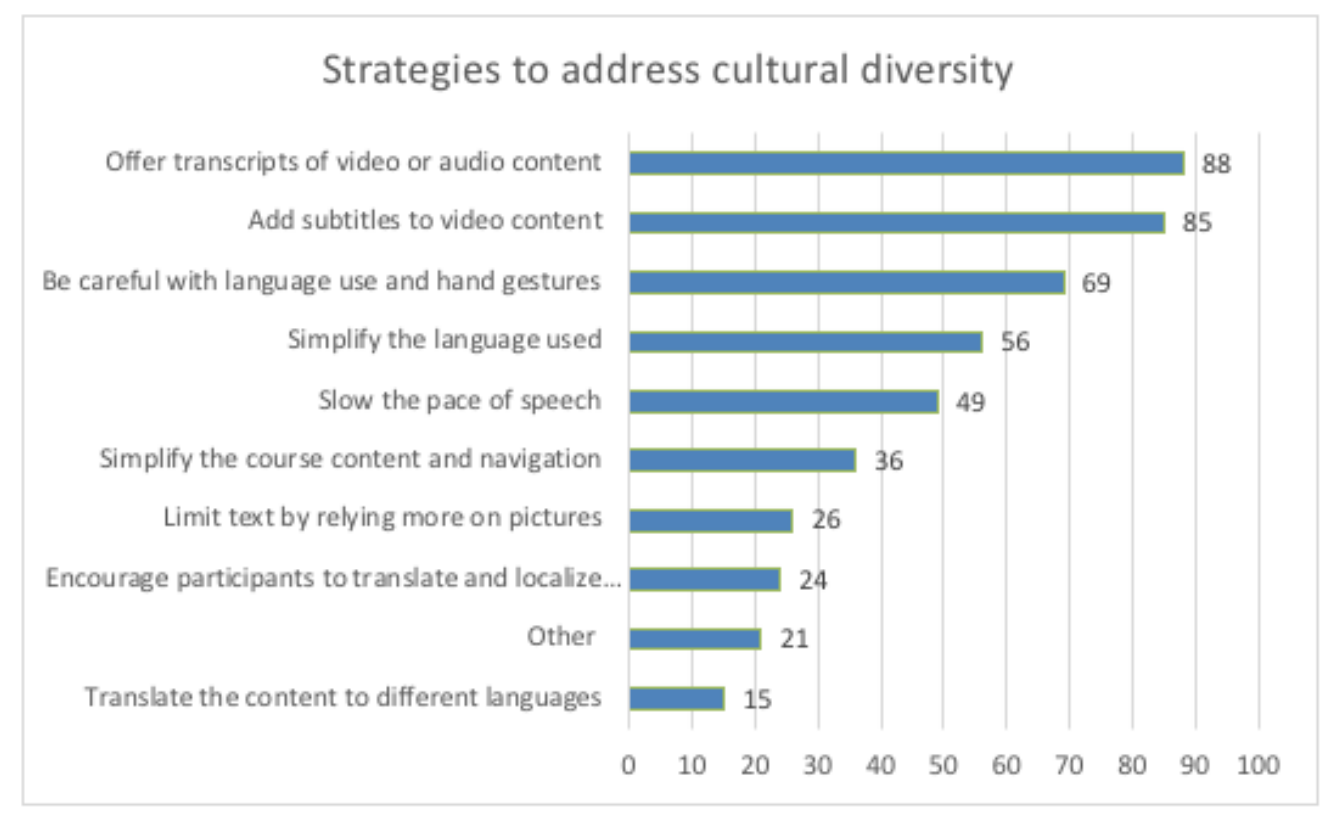

Figure 4. MOOC Instructors' Instructional Practices to Address Cultural Diversity ( $\mathrm{n}=133$ ) 


\section{QUALITATIVE DATA ANALYSIS RESULTS}

\section{MOOC and Open Education Experts}

As indicated in the method section, we conducted two rounds of interviews with the MOOC and open education experts regarding cultural sensitivity and personalization of MOOCs. These experts were given examples such as being cognizant that images of certain hand gestures or body movements may offend people or not be part of societal norms. Also mentioned to the experts was the problem of case situations or scenarios involving alcohol, the incorporation of pictures of dogs in the Middle East, political humor and satire, the use of quotes from religious leaders, and incorporating YouTube videos (which are not accessible in cultures like China). In addition, it was mentioned that clothing, hairstyle, music, jokes, and reliance on the English language can all be problematic.

That long prompt fostered many ideas, personal anecdotes, and suggestions. As noted in Table 3, these MOOC and open education experts had a wide range of recommendations related to cultural sensitivity. Some related to content design, whereas others related to the delivery of MOOC instruction. A few of these experts offered ideas related to the overall learning environment or ecology of the MOOC such as encouraging participants to support each other with lower bandwidth versions of MOOC videos as well as to find ways to translate the MOOC content to local language and cultural needs.

Table 3. Best Practice Recommendations by MOOC and Open Education Experts for Addressing Cultural Sensitivity $(\mathrm{n}=25)$

\begin{tabular}{|c|c|c|}
\hline MOOC Stage & Category & Approach \\
\hline \multirow[t]{19}{*}{ Design } & Communication & $\begin{array}{l}\text { Provide possible alternative back channels for traditional discussion boards (e.g., } \\
\text { WhatsApp, WeChat, KakaoTalk, etc.). }\end{array}$ \\
\hline & & $\begin{array}{l}\text { Consider the different ways learners read information - Some languages are not } \\
\text { presented in a linear format. }\end{array}$ \\
\hline & Course design & $\begin{array}{l}\text { Leverage straightforward course designs as intricate or nested course designs can be } \\
\text { difficult to convert across languages and platforms. }\end{array}$ \\
\hline & & $\begin{array}{l}\text { Ensure visual examples (i.e., icons and caricatures) repeated throughout the course } \\
\text { appeal to as many stakeholders as possible. }\end{array}$ \\
\hline & Media use & $\begin{array}{l}\text { Consider different audiences through perspective taking when incorporating } \\
\text { multimedia. }\end{array}$ \\
\hline & & $\begin{array}{l}\text { Overreliance on visual rhetoric (e.g., visual images) alone to communicate can be } \\
\text { problematic. }\end{array}$ \\
\hline & & $\begin{array}{l}\text { Use caution when including videos on an external website, such as YouTube, as content } \\
\text { could be restricted for certain users. }\end{array}$ \\
\hline & & $\begin{array}{l}\text { Remember that converting text into various languages is easier than videos, and it } \\
\text { takes much longer to create a video. }\end{array}$ \\
\hline & & $\begin{array}{l}\text { Slideshows should not overwhelm learners with text; try to use symbols, icons, and } \\
\text { other visual elements. }\end{array}$ \\
\hline & $\begin{array}{l}\text { Reuse and } \\
\text { remix }\end{array}$ & $\begin{array}{l}\text { Ensure inclusivity by openly licensing all educational materials developed for MOOCs, } \\
\text { to guarantee the permissions and freedoms required for translation, adaptation, re-use, } \\
\text { redistribution, and repackaging. }\end{array}$ \\
\hline & & Understand the legal differences and barriers between copyright, copyleft, and public. \\
\hline & & $\begin{array}{l}\text { Consider the technology used in development. Ask yourself, "Does it assist reuse and } \\
\text { remixing?" }\end{array}$ \\
\hline & & $\begin{array}{l}\text { Weigh the potential of other instructors' capabilities in remixing/reusing the content } \\
\text { and provide support where appropriate. }\end{array}$ \\
\hline & $\begin{array}{l}\text { Technology } \\
\text { accessibility }\end{array}$ & $\begin{array}{l}\text { Appreciate the power of mobile learning! In many regions of the world, learning } \\
\text { occurs through mobile devices. Courses should be pedagogically and technologically } \\
\text { developed with this mindset. }\end{array}$ \\
\hline & & Identify the range of learner digital literacy skills. \\
\hline & & $\begin{array}{l}\text { Encourage learners to create low bandwidth versions of multimedia for those in low } \\
\text { bandwidth areas. }\end{array}$ \\
\hline & & $\begin{array}{l}\text { Foster a learner community where learners help learners in downloading, translating, } \\
\text { and hosting multimedia. }\end{array}$ \\
\hline & $\begin{array}{l}\text { Working with a } \\
\text { design team }\end{array}$ & $\begin{array}{l}\text { Encourage courses/content to be developed by teams consisting of members for } \\
\text { various institutions, countries, and/or cultures. }\end{array}$ \\
\hline & & Actively prepare MOOC instructors and online course designers for cultural sensitivity. \\
\hline
\end{tabular}




\begin{tabular}{|c|c|c|}
\hline \multirow[t]{15}{*}{ Delivery } & \multirow{2}{*}{$\begin{array}{l}\text { Attire and } \\
\text { mannerisms }\end{array}$} & Remain presentable and well-dressed when appearing in multimedia. \\
\hline & & $\begin{array}{l}\text { Be thoughtful about body movement and overall gestures, as well as images of hand } \\
\text { gestures, as different cultures decipher meaning in diverse ways. }\end{array}$ \\
\hline & \multirow[t]{3}{*}{ Culture specific } & $\begin{array}{l}\text { Asian audiences may not be the quickest to voice their opinions and prefer to be spoken } \\
\text { to with deference, politely, and softly. }\end{array}$ \\
\hline & & $\begin{array}{l}\text { Not all learners read left to right. For example, some Middle Eastern learners read } \\
\text { content right to left, and some Asian learners read content top to bottom. }\end{array}$ \\
\hline & & $\begin{array}{l}\text { Content including case situations or scenarios involving alcohol, the incorporation of } \\
\text { pictures of dogs (from some nations), political humor/satire, and the use of quotes from } \\
\text { religious figures can prove to be controversial and potentially offensive. }\end{array}$ \\
\hline & \multirow{4}{*}{$\begin{array}{l}\text { Developing } \\
\text { a sense of } \\
\text { community }\end{array}$} & Avoid references to current events that may only be shared by a small subgroup. \\
\hline & & $\begin{array}{l}\text { Urge learners to meet locally or amongst themselves to share materials and address any } \\
\text { sensitive concerns. }\end{array}$ \\
\hline & & Avoid issues related to religion and politics. \\
\hline & & $\begin{array}{l}\text { Minimize distractions and possible negative responses by staying away from } \\
\text { controversial topics. }\end{array}$ \\
\hline & \multirow[t]{2}{*}{$\begin{array}{l}\text { Emphasis on } \\
\text { expertise }\end{array}$} & $\begin{array}{l}\text { Respect the deep-seated cultural differences related to the following: the value of } \\
\text { expert vs. learner-originated knowledge; deference to experts; and willingness to } \\
\text { engage in discussion and critique - with the most noticeable contrasts between those } \\
\text { educated in Anglo-Saxon education systems and in Confucianist ones. }\end{array}$ \\
\hline & & $\begin{array}{l}\text { Have instructions/directions at the ready, just as a backup, for those who tend to respect } \\
\text { authority and prefer following directions. }\end{array}$ \\
\hline & \multirow[t]{4}{*}{$\begin{array}{l}\text { Language and } \\
\text { translations }\end{array}$} & $\begin{array}{l}\text { Make subtitles and transcriptions, when possible, available in multiple languages based } \\
\text { on intended audiences. This also empowers hard of hearing learners. }\end{array}$ \\
\hline & & $\begin{array}{l}\text { Even when English is the primary or secondary language of the target audience, } \\
\text { consider making MOOC content available in the major dialect(s) of the country. }\end{array}$ \\
\hline & & $\begin{array}{l}\text { Identify any cultural aspects of resources disseminated as understandings and } \\
\text { meanings may not be exact when translated; each linguistic group has its own scientific } \\
\text { history and culture. }\end{array}$ \\
\hline & & Jokes and humor, in general, can be easily misinterpreted. \\
\hline
\end{tabular}

The second round of interviews with most of these experts $(n=19)$ identified instructional design elements that assisted MOOC instructors in personalizing their course for cultural diversity and technology accessibility. Principle among these elements was changing course assignments to be "collaborative projects" and allowing learners to engage in "small group learning." Four of the 19 experts interviewed in round two noted instances of increased learner motivation from these elements and attributed it to learner empowerment. Instructors also mentioned increased formations of learning networks and personal connections as learners engaged in the MOOC via group work and by self-selecting tasks and/or groups.

Qualitative analysis revealed disagreement about best practices to account for cultural multiplicity when grouping learners. Some instructors practiced grouping learners with similar backgrounds and interests to become a "cohort that has similar learning goals, or that is interested in supporting their own learning goals." Others believed in creating "mixed group $[\mathrm{s}]$ to see if there are any differences of opinions" to promote dialogues of difference. Even though the methods of group creation vary, the online questionnaire data support small-group learning as a personalization tool for enhanced cultural understanding and awareness. Correspondingly, some MOOC instructors reported that they either personally assigned learner groups or used the learning management system to do so, whereas other instructors reported using pair-based assignments to encourage learner interactions.

\section{Survey Respondents}

In one of the open-ended questions, the researchers probed further about how these instructors designed their MOOCs to make them easier to access for learners with different backgrounds and technology access. Many of the MOOC instructors provided quite pertinent and thoughtful responses to this question. Among them, one person who likely taught a MOOC in the area of political science stated that: "Our content covered examples from different political and religious contexts, across Europe, the Americas, the Middle East and Asia, designed in turn to encourage learners from diverse backgrounds to share their own political experience." Another respondent noted that his or her course followed the "UK accessibility compliance 
guidelines" and the key course materials were made available at an elementary level while more complex materials were embedded in the form of supplemental readings and case studies for those who wished to delve more deeply into the content. Additional examples of providing greater access to course content included working with university experts, consulting with language departments, and piloting content with international learners and friends from countries like "Jordan, China, Greece and Turkey" and then debriefing and discussing it with them. Another example is, "All videos and screencasts had transcriptions available to read. Our MOOC platform was designed to allow users to view the MOOC material on a computer, tablet, or smartphone."

One survey respondent had a vast repertoire of strategies to address the various participant cultures and backgrounds that are typical in MOOCs. This individual stated:

"I use a platform that I know is reasonably good across browsers and operating systems. I do not use anything which is flash-based. I test material on different devices. I make navigation as easy as possible. I offer multiple communication channels. I do not comment on language or grammar when commenting on forum posts. I caption videos and supply transcripts, though I do make it clear the course is developed in English. I have a long history of teaching learners from other countries so I am conscious about creating material that is accessible from cultures other than the UK."

The survey respondents also commented on specific instructional practices adopted to address the cultural and linguistic differences amongst learners. While most of the responses were centered on adopting the MOOC for linguistic diversity, some instructors elaborated on other aspects of accommodating for cultural diversity in MOOC design. A professor of engineering stated that he "adapt $[\mathrm{s}]$ assignment $[\mathrm{s}]$ to fit... different cultures." The questions asked instructors to describe not only their cultural diversity adaptations, but also their methods for improving technology access. As MOOC instructors varied in subject area expertise, and national origin, their involvement in addressing culture and language differences was quite varied as well.

One open-ended question asked about the instructional practices that were used to address different cultural backgrounds as well as technology access among learners $(n=35)$. The responses of these instructors are reported in Table 4. Multimedia presentations, optional resources, course instruction and language, feedback, collaboration, technology access, and varied communication channels were some of the approaches that instructors used to address diversity during the MOOC design stage. The top four ways related to how MOOC instructors design their courses in consideration of learners' background and technology access included: (1) providing captions and transcriptions to all videos and screencasted materials. Importantly, this strategy was intended to accommodate learners with disabilities or different learning styles; (2) offering supplemental or optional materials; (3) making sure that all materials can be viewed on an assortment of devices, including computers, tablets, or smartphones. Moreover, some instructors experimented with the look of their materials on smartphones of different sizes; and (4) keeping the course materials at the level of a non-expert. Such an approach was intended to limit the tension and stress of MOOC learners who come from different fields, while, at the same time, not neglecting learners who wanted to study more deeply by offering additional learning materials.

Further information on what various MOOC instructors in this survey attempted is detailed in Table 4. While approaches of MOOC instructors may slightly vary from MOOC experts, categories overlap. A noted difference between Table 3 and 4's compilation of approaches is the level of specificity and breadth of the discourse in Table 3, whereas Table 4 presents central themes. Both collections of approaches provide valuable insight for addressing cultural sensitivity with MOOC environments. 
Table 4. Approaches Employed by MOOC Instructors to Enhance Access for Learners with Different Backgrounds and Technology $(\mathrm{n}=35)$

\begin{tabular}{|c|c|}
\hline Category & Approach \\
\hline \multirow[t]{2}{*}{ Collaboration } & $\begin{array}{l}\text { Work alongside various university divisions (e.g., international office, student support, } \\
\text { university expert, and language department). }\end{array}$ \\
\hline & Pilot the course with international learners. \\
\hline \multirow{3}{*}{$\begin{array}{l}\text { Communication, feedback, } \\
\text { and language }\end{array}$} & Offer multiple communication channels. \\
\hline & Use simple, slow, and clear language. \\
\hline & Do not focus on language or grammar when commenting on forum posts. \\
\hline \multicolumn{2}{|l|}{ Content } \\
\hline & Create material that is acceptable for various cultures. \\
\hline & Keep cultural differences in mind when designing and producing the material. \\
\hline & Emphasize materials which accommodate for various learning preferences. \\
\hline & Share personal stories, to some degree, by recording lessons in and around personal spaces. \\
\hline & Follow target country's compliance rules and regulations. \\
\hline \multirow[t]{4}{*}{ Course instruction } & Ensure material is kept at a non-expert level. \\
\hline & Provide detailed outlines of the lesson. \\
\hline & Arrange open course work where everyone can choose to work individually. \\
\hline & Provide background information and course expectations. \\
\hline \multirow[t]{5}{*}{ Multimedia use } & Strive to include captioned or transcribed videos and screencasts. \\
\hline & Ensure videos are kept simple and short and include animations in presentations. \\
\hline & Leverage free textbooks and open resources. \\
\hline & Attempt to provide PDF documents and Word version of materials. \\
\hline & Provide text reader or read aloud options, when possible. \\
\hline Optional resources & Offer supplemental or optional materials. \\
\hline \multirow[t]{6}{*}{ Technology accessibility } & $\begin{array}{l}\text { Course materials should be device agonistic, easy to use, and easy to access. Materials can } \\
\text { be used on a computer, tablet, smartphone application, or mobile phone. }\end{array}$ \\
\hline & Provide materials that use low bandwidth and make class activities browser based. \\
\hline & $\begin{array}{l}\text { Make multimedia interactive apps more user-friendly by not engaging Flash-based } \\
\text { platforms. }\end{array}$ \\
\hline & Encourage simple navigation. \\
\hline & Create user-directed FAQs. \\
\hline & Videos and transcripts should be available for download later. \\
\hline
\end{tabular}

In the following discussion section, we reflect on some of the cultural sensitivity suggestions and advice from the MOOC and open education experts listed in Table 3 as well as the recommendations of the MOOC instructor survey respondents noted in Table 4. We also reflect on our other survey findings.

\section{DISCUSSION}

The first of the key research questions providing an impetus for this mixed-methods study sought to better understand the degree to which MOOC instructors and their instructional design teams were creating learning environments that accommodated the cultural and linguistic diversity of the participants. Results of the online survey indicate that these MOOC instructors were placing modest efforts in addressing the cultural, linguistic, and other needs of their MOOC participants in their most recent MOOC. Nevertheless, nearly one in three of these instructors indicated that they placed high effort and attention on this issue when designing and delivering their MOOCs. Suffice to say, their responses were quite varied.

The second research question was related to the in-class instructional practices that MOOC instructors rely upon to address diverse learner needs and backgrounds. As part of such efforts, MOOC personalization practices were explored. While half of these instructors rated themselves as having limited prior experience 
in teaching blended or fully online learning courses, they were experimenting with many different types of instructional methods to address participants from different cultural and linguistic backgrounds.

According to the survey data, among the most common adaptations of content was to provide transcripts of video and audio content as well as embedding subtitles with video content. Slightly more than half of the instructors were also aware of the need to be careful with their language use and hand gestures; in particular, many were self-aware of their rate of speech in their video lectures. Some were concerned about the complexity of the content as well as the navigation within that content. The preference for text over pictures was also an indication that they were sensitive to bandwidth issues. And some MOOC instructors designed courses in multiple languages.

While these were general strategies or approaches that instructors used to address their diverse populations, there were many more specific tactics mentioned in the open-ended survey items as well as in the earlier email interviews of MOOC and open education experts. Among these tactics included creating user-directed FAQs, utilizing case studies, asking international learners to pilot the content, organizing schedules of the instructional team to address student concerns in the discussion forums, keeping video content under a certain length limit, testing content on different platforms, and not commenting on participant language or grammar use. They also relied on many different technologies to accomplish these goals, including social media such as Twitter and Facebook, screencast technology, shared online videos, and synchronous Web conferencing.

We should also point out that some of the instructors were very conscious of the power of crowds. As observed by Kim and Chung (2015), nearly one in five MOOC instructors we surveyed indicated that they encouraged their participants to translate and localize content for their peers. Such volunteer services for one another may be a factor which is unaccounted for in much of the prevailing MOOC research and deserves some follow-up. For instance, examples of MOOC participant crowdsourcing may improve the attitudes towards MOOCs and their overall sustainability.

The qualitative coding of the interview data added to the insights. Addressing cultural diversity in MOOCs is multifaceted. As shown by both Table 3 and Table 4, there are an assortment of instructional variables for instructors to ponder related to the technology use and accessibility, the design of multimedia presentations, the forms and type of content, supplemental resources provided, feedback mechanisms and approaches, pace of language, communication channels established, collaboration tactics employed, and the degree and type of course instructions and task structuring. Clearly, teaching a MOOC stretches the edges of one's instructional abilities and prowess.

MOOC instructor participants in this study echoed the suggested approaches of Bates and Poole (2003) and Moore and Kearsey (2005), where relying on a singular technology or approach did not meet the learning needs of all learners. In terms of this issue, MOOC instructors in the current study tended to create learning environments that used several technologies in varying interaction modes to overcome course specific problems. Through the narrative responses and interviews, it became evident that the MOOC instructors did not have a singular understanding of culture. Some MOOC instructors interpreted 'culture' by referring to nation specific approaches, while others related culture with certain language competencies.

Overall, the findings from this study indicate that MOOC instructors see a need to adapt their courses in both design and delivery to better address cultural diversity. Strategies such as collaborative, small groupbased assignments and adaptation of instructional content for specific cultures and nationalities are steps in the right direction (Gunawardena et al., 2019; Sieffert, 2006). Furthermore, many MOOC instructors not only attempt to address diversity in their course resources and activities, but also collaborate with various university departments and international learners in preparing the learning materials.

Across out research questions related to cultural sensitivity and personalization in the design and delivery of MOOCs, there were many recommendations and suggestions. In this study, most MOOC instructors focused on strategies to address cultural and linguistic diversity by supplementing video with text, providing text with video or audio, and being cautious with gestures. Besides such solutions, other strategies that were utilized included the adaptation of instructional content for specific populations and multimedia usage. Of course, this is just the start of a long evolution of addressing cultural diversity and personalizing MOOCs and other forms of open education. 


\section{LIMITATIONS}

One of our key limitations relates to our database of MOOC instructors. More specifically, while we had collected the course and contact information for over 1,000 MOOC instructors from dozens of countries, such data for courses outside of English-speaking countries was limited by the lists provided. And, while most of the lists from which we gathered data were from the United States, there are still more such lists that we could mine. In response, we continue to expand our database of MOOC instructors. Another limitation is that the survey was voluntary or opt-in; as such, it is plausible that MOOC instructors who completed this survey were more attuned with how to address cultural differences and personalize their courses than those who did not participate. A third limitation was that the researchers did not evaluate MOOC courses to evaluate the validity of self-reporting. Additional follow-up research is warranted to understand the approaches that were deemed successful in MOOCs and how instructors modified them over time. Finally, MOOCs and other forms of open education remain a relatively new and fast changing field of study. The technologies and instructional practices related to teaching a MOOC are still evolving; especially in terms of adapting to diverse learner needs and experiences. Given these various limitations, any results here should be viewed as preliminary and evolutionary.

\section{FUTURE DIRECTIONS}

Millions of people are impacted each day by emerging technologies for designing and delivering education, such as MOOCs and other forms of open education. Consequently, there is a mounting need for MOOC and open education instructors to better empathize with and adapt to their learning participants. Followup interviews and focus groups based on our findings, either with some of our original MOOC instructor survey participants or with others from our expanded database of 3,200 MOOC instructors, might prove particularly interesting and significant. There is also a need to interview other MOOC and open education experts as well as MOOC learners. Future research might explore how to build awareness of not only the need to be more culturally sensitive in the design and delivery of MOOCs, but also the instructional strategies and approaches that are proven to be effective. Of course, this research might also explore cost variables and scalability measures related to different instructional approaches and strategic initiatives for addressing participant diversity.

This study showed that MOOC instructors are attempting to understand and better address the challenges and problems related to cultural differences. Unfortunately, while Tables 3 and 4 are intended to offer some inroads, at present there is no universal understanding of cultural diversity and definitive best practices in this area. In addition to retrospective interviews, real-time interviews during course delivery are now needed to better understand the instructors' practices and ideas related to addressing cultural diversity in MOOC design. Given the enormous scale of these courses and the global impact, it is vital for such research to result in a set of guidelines and best practices to address learner diversity.

Research is also needed on how different types of MOOCs and hybrid models might be used to better address learners from different cultural, social, educational, political, and linguistic backgrounds. As part of such efforts, content analyses of MOOCs as well as direct observation or participation in a range of MOOCs might lend insight into the MOOC-related components and approaches that tend to entail greater cultural inclusivity and sensitivity.

As we continue to expand our list of MOOC instructors, we are beginning to also address the learner side of the equation. It is vital to attempt to align perceptions of MOOC instructors regarding cultural sensitivity with those of their MOOC participants and vice versa. This large database of MOOC instructors also allows us to target our research efforts in specific countries (e.g., Malaysia, Indonesia, China, Korea, etc.) and regions of the world (Zhu, Bonk, \& Sari, 2019).

Clearly, there are so many directions for research in this field to proceed. For instance, as groundbreaking advances occur in learning technologies, such as artificial intelligence, personal digital assistants, and virtual and augmented reality, so, too, must educators and researchers think beyond the stakeholders and learners in their country or region of the world to those who might benefit later or in a different way or scale from today. How might MOOCs be designed, delivered, and evaluated in ways that reach out to learners in the Global 
South and beyond (Gunawardena, 2014; Zhang, Bonk, Reeves, \& Reynolds, 2020)? MOOC localization in the form of J-MOOCs (Japanese MOOCs), K-MOOCs (Korean MOOCs), Thai MOOCs, and so on, is one clear result.

\section{IMPLICATIONS AND CONCLUSIONS}

It is evident from these findings that instructors are making strides in addressing issues of cultural and linguistic diversity when designing and implementing their MOOCs. Our research indicates that many MOOC instructors have begun a reflection process on how to improve their next MOOC offerings in terms of addressing learner diversity and linguistic differences. However, while these MOOC instructors are attempting to better understand and address the participants in their MOOCs, much more could be done. The present study does offer some guidance and perhaps a hint of optimism or hope to those who are considering becoming a MOOC instructor.

Given the trendlines of MOOCs, the next wave of MOOCs and MOOC instructors will continue to impact hundreds of millions of learners each year (Shah, 2015, 2016, 2019). As such, the diversity of the participants of such massive courses will not subside. What is certain is that additional studies that expand upon the present one are crucial.

There is a pressing need to better understand how MOOCs can address learner diversity and cultural backgrounds. This study of 25 MOOC and open education experts, as well as 152 MOOC instructors, offers insights about how this can be accomplished in both MOOC design and implementation. The results can inform instructional designers, instructors, and policy makers of what is required for higher quality and more effective MOOC experiences. Since thousands of MOOC instructors around the planet are waiting, we will keep expanding our database of MOOC instructors and MOOC courses in the hopes of making additional contributions soon.

Acknowledgements: We would like to thank Drs. Mimi M. Lee, Thomas C. Reeves, and Thomas H. Reynolds who helped collect the expert interview data on MOOC cultural sensitivity and personalization strategies and practices reported here.

\section{BIODATA and CONTACT ADDRESSES of AUTHORS}

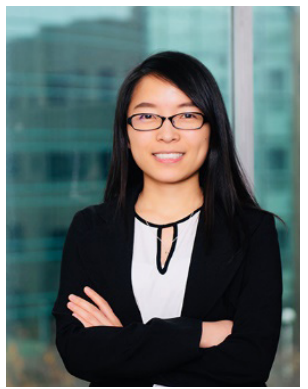

Dr. Meina ZHU is an assistant Professor in the Learning Design and Technology program in the College of Education at Wayne State University. Meina Zhu gained her Ph.D. in Instructional Systems Technology at July, 2019. Her academic interest areas are online education, open education and MOOCs, self-directed learning, STEM education, and active learning. She has over than 24 peer-reviewed journal articles published, 1 international book chapter and other national and international articles, papers submitted to international meetings.

Meina ZHU

Learning Design and Technology, College of Education

Address: Wayne State University, 48402, Detroit, the United States

Phone: +01 313-577-7822

E-mail: meinazhuiu@gmail.com 


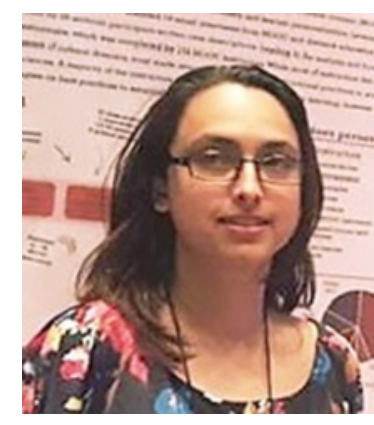

Najia SABIR is the Lead Accessibility Architect at Management Concepts where she ensures that Section 508 conformance is addressed during every phase of a project's life cycle. She is also a $\mathrm{PhD}$ Candidate and former associate instructor at Indiana University - Bloomington seeking a degree in Instructional Systems Technology. Her research interests are: 21st century learning skills, educator empowerment and techquity, educational technology, teacher development and values, global education and collaboration. Najia has nearly nine years of formal teaching experience across three nations (US, India, and South Korea), and has worked as a technology consultant in DC, where she frequently instructed faculty/ staff. Additionally, Najia taught collegiate courses (introductory and advanced) at Indiana University. At Management Concepts, Najia is engaged with streamlining the company's workflow for accessible design and development practices.

Najia SABIR

Instructional Systems Technology, School of Education

Address: 201 North Rose Avenue, Bloomington, IN, USA, 47405-1006

Phone: 703-270-4053

Email: nsabir@iu.edu

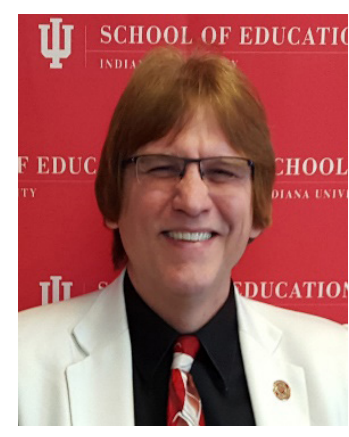

Dr. Curtis J. BONK is Professor at Indiana University teaching psychology and technology courses and President of CourseShare. Drawing on his background as a corporate controller, CPA, educational psychologist, and instructional technologist, Bonk offers unique insights into the intersection of business, education, psychology, and technology. His academic interests are in online learning, MOOCs, open education, collaborative technology, informal learning, emerging learning technologies, self-directed learning, and blended learning. He has authored many widely used technology books, including The World Is Open, Empowering Online Learning, The Handbook of Blended Learning, Electronic Collaborators, Adding Some TEC-VARIETY which is free as an eBook (http://tec-variety.com/), and MOOCs and Open Education Around the World as well MOOCs and Open Education in the Global South (http://www.moocsbook.com/). Bonk has published more than 130 journal articles and 60 book chapters. In 2020, he was awarded the IU President's Award for Excellence in Teaching and Learning Technology. Curt can be contacted at cjbonk@indiana.edu and http://curtbonk.com/.

Curtis J. BONK

Instructional Systems Technology, School of Education Address: Indiana University, 201 N. Rose Avenue, Bloomington, IN, USA 47405

Phone: +1-812-322-2878

E-mail: cjbonk@indiana.edu 


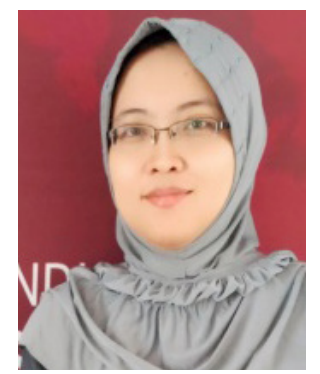

Annisa Ratna SARI is a Ph.D. candidate in Instructional Systems Technology at Indiana University Bloomington, US and lecturer in Accounting Education department at Yogyakarta State University, Indonesia. Her main research interest is the use of online learning and blended learning in the higher education setting. In addition, she is also interested in financial literacy education in the K-12 setting. She has published several journal articles and books during her career as academician since 2005.

\section{Annisa Ratna SARI}

Accounting Education Department, Yogyakarta State University

Address: Fakultas Ekonomi UNY Karangmalang Yogyakarta, 55281, Indonesia

Phone: +62 (274) 554902

E-mail: annisa@uny.ac.id

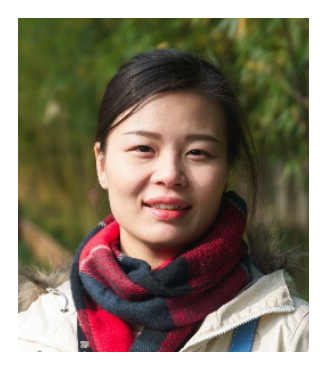

Dr. Shuya XU is the lead instructional designer at TechSoup Learning. Dr. Shuya Xu received her Ph.D. in Instructional Systems Technology from Indiana University in May 2019. Her academic interest areas are self-directed e-learning, online learning communities, personalized learning, and emerging educational technologies. Shuya has diverse instructional design experience in corporate and higher education settings, creating and delivering online, blended, and face-to-face learning to a wide range of audiences. At TechSoup, she leads the design and development of various online training solutions for nonprofit organizations around the world.

\section{Shuya XU}

TechSoup Learning

Address: TechSoup, 94107, San Francisco, USA

Phone: +01 812-606-0570

E-mail: sczxushuya@gmail.com

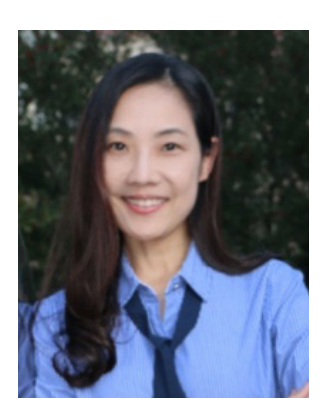

Dr. Minkyoung KIM is an assistant professor in the Department of Instructional Design and Technology at the University of West Florida. Dr. Kim earned a doctoral degree in Instructional Systems Technology from Indiana University at July, 2016 and bachelor's and master's degrees in the same field at Ewha Womans University in Korea. Her research interests center on instructional design theories related to the learner-centered paradigm, personalized learning, collaborative learning, instructional supports in project-based learning as well as quality of online education. She received the AECT award for outstanding instructional design project in 2014, the AECT emerging scholar award in 2015, and the outstanding article award in 2020. Her research efforts have also resulted in co-authored publications, handbook chapters, and numerous conference and classroom presentations.

\section{Minkyoung KIM}

Instructional Design and Technology, College of Education and Professional Studies

Address: University of West Florida, 32015, Pensacola, USA

Phone: +1 812-361-0334

E-mail: kim@uwf.edu 


\section{REFERENCES}

Ahn, M. L., Yoon, H., \& Cha, H. (2015). Cultural sensitivity and design implications of MOOCs from Korean learners' perspectives: Case studies on edX and Coursera. Educational Technology International, 16(2), 201-229. Retrieved from http://www.kset.or.kr/eti_ojs/index.php/instruction/article/ view/49/pdf_15

Alony, I., Kaye, S. B., \& Lambert, S. R. (2015). MOOCs' contribution to staff development and capacity building: Australian University Case study. Paper presented at the 26th International Council for Open and Distance Education World Conference, Growing capacities for sustainable distance e-learning provision, Sun City, South Africa. Retrieved from https://ro.uow.edu.au/cgi/viewcontent. cgi? referer=https://scholar.google.com/\&httpsredir=1\&article=1531\&context=asdpapers

Bates, A. W., \& Poole, G. (2003). Effective teaching with technology in higher education: Foundations for success. San Francisco, CA: Jossey-Bass.

Belanger, Y., \& Thornton, J. (2013, February 5). Bioelectricity: A quantitative approach Duke University's first MOOC. Duke University, North Carolina. Retrieved from http://dukespace.lib.duke.edu/ dspace/handle/10161/6216.

Bentley, J. P., Vawn-Tinney, M., \& Chia, B. H. (2005). Intercultural internet-based learning: Know your audience and what it values. Educational Technology Research \& Development, 53(2), 117-127. Retrieved from https://link.springer.com/content/pdf/10.1007\%2FBF02504870.pdf

Boga, S., \& McGreal, R. (2014). Introducing MOOCs to Africa: New economy skills for Africa programICT. Commonwealth of Learning's Open Access Institutional Repository. Retrieved from http://oasis. col.org/bitstream/handle/11599/613/MOOCs_in_Africa_2014_Boga-McGreal.pdf?sequen

Bogner, A., Littig, B., \& Menz, W. (2009). Introduction: Expert interviews - an introduction to a new methodological debate. In A. Bogner, B. Littig and W. Menz (Eds.), Interviewing experts (pp. 1-16). Hampshire, UK: Palgrave Macmillan.

Bonk, C. J., Zhu, M., Kim, M., Xu, S., Sabir, N., \& Sari, A. (2018). Pushing toward a more personalized MOOC: Exploring instructor selected activities, resources, and technologies for MOOC design and implementation. The International Review of Research on Open and Distributed Learning, 19(4), 92-115. Retrieved from: http://www.irrodl.org/index.php/irrodl/article/view/3439/4726

Breslow, L., Pritchard, D. E., DeBoer, J., Stump, G. S., Ho, A. D., \& Seaton, D. T. (2013). Studying learning in the worldwide classroom research into edX's first MOOC. Research \& Practice in Assessment, 8, 13-25. Retrieved from https://files.eric.ed.gov/fulltext/EJ1062850.pdf

Callaway, R., Matthew, K., \& Felvegi, E. (2014, June). Blackboard options for culturally accessible online courses. Proceedings of the World Conference on Educational Multimedia, Hypermedia and Telecommunications (Vol. 2014, No. 1, pp. 3886-3888), Chesapeake, VA: Association for the Advancement of Computing in Education (AACE). Retrieved from https://www.learntechlib. org/p/147742/

Cho, H., \& LaRose, R. (1999). Privacy issues in Internet surveys. Social Science Computer Review, 17(4), 421-434. https://doi.org/10.1177/089443939901700402

Christensen, G., Steinmetz, A., Alcorn, B., Bennett, A., \& Woods, D. (2013, November 6). The MOOC phenomenon: Who takes massive open online courses and why? University of Pennsylvania. Retrieved from http://papers.ssrn.com/sol3/papers.cfm?abstract_id=2350964

Chuang, I., \& Ho, A. (2016, December 23). HarvardX and MITx: Four years of open online courses-fall 2012-summer 2016. Retrieved from https://papers.ssrn.com/sol3/papers.cfm?abstract_ id $=2889436$ or http://dx.doi.org/10.2139/ssrn.2889436

Cormier, D., \& Siemens, G. (2010). Through the open door: Open courses as research, learning, and engagement. EDUCAUSE Review, 45(4), 30-39. Retrieved from http://er.educause.edu/ articles/2010/8/through-the-open-door-open-courses-as-research-learning-and-engagement 
Creswell, J. W., \& Plano-Clark, V. L. (2017). Designing and conducting mixed methods research (Third ed.). Thousand Oaks, CA: Sage.

Czerniewicz, L., Deacon, A., Small, J., \& Walji, S. (2014). Developing world MOOCs: A curriculum view of the MOOC landscape. Journal of Global Literacies, Technologies, and Emerging Pedagogies, 2(3), 122-139. Retrieved from https://open.uct.ac.za/bitstream/handle/11427/19562/2._Developing world_MOOCs.pdf?sequence $=1$ \&isAllowed=y

Dekena, G. (2012, November 28). The original, free online AI class, now on Udacity! Udacity. Retrieved from https://blog.udacity.com/2012/11/ai-class-now-on-udacity.html

Ebben, M., \& Murphy, J. S. (2014). Unpacking MOOC scholarly discourse: A review of nascent MOOC scholarship. Learning, Media and Technology, 39(3), 328-345. https://doi.org/10.1080/1743988 4.2013.878352

Edmundson, A. L. (2005). The cross-cultural dimensions of globalized e-learning. International Journal of Information and Communication Technology Education (IJICTE), 1(2), 47-61. Retrieved from https://www.igi-global.com/article/cross-cultural-dimensions-globalized-learning/2261

Fail, H. (2011). Teaching and learning in international schools: A consideration of the stakeholders and their expectations. In R. Bates (Ed.), Schooling internationally: Globalization, internationalization and the future for international schools (pp. 101-120). New York, NY: Routledge.

Fereday, J., \& Muir-Cochrane, E. (2006). Demonstrating rigor using thematic analysis: A hybrid approach of inductive and deductive coding and theme development. International Journal of Qualitative Methods, 5(1), 80-92. https://doi.org/10.1177/160940690600500107

Fini, A. (2009). The technological dimension of a massive open online course: The case of the CCK08 course tools. The International Review of Research in Open and Distributed Learning, 10(5), 14-26. Retrieved from http://www.irrodl.org/index.php/irrodl/article/view/643/1402

Ford, G., \& Kotze, P. (2005, September). Designing usable interfaces with cultural dimensions. In IFIP Conference on Human-Computer Interaction -INTERACT 2005 (pp. 713-726). Berlin, Germany: Springer

Glaser, B. G., \& Strauss, A. L. (2009). The discovery of grounded theory: Strategies for qualitative research. New Brunswick, NJ: Transaction publishers.

Gobbo, L. D., Nieckoski, M., Rodman, R., \& Sheppard, K. (2004). Virtual limits: Multicultural dimensions of online education. International Educator, 13(3), 30-39. Retrieved from https://search.proquest. com/openview/1806263dddf15508992e4547e8a7230f/1?cbl=44755\&pq-origsite=gscholar

Goulding, C. (2002). Grounded theory: A practical guide for management, business and market researchers. Thousand Oaks, CA: Sage.

Gunawardena, C. (2014, March 19). MOOCs: Students in the global south are wary of 'a sage on a stage.'The Guardian. https://www.theguardian.com/education/2014/mar/19/cost-barrier-students-globalsouth

Gunawardena, C. N. (2020). Culturally inclusive online learning for capacity development projects in international contexts. Journal of Learning for Development, 7(1), 5-30. Retrieved from https:// jl4d.org/index.php/ejl4d/article/view/403/453

Gunawardena, C., Frechette, C., \& Layne, L. (2019). Culturally inclusive instructional design: A framework and guide to building online wisdom communities. New York, NY: Routledge.

Halawa, S., Greene, D., \& Mitchell, J. (2014). Dropout prediction in MOOCs using learner activity features. Proceedings of the Second European MOOC Stakeholder Summit, 37(1), 58-65. Retrieved from https://www.researchgate.net/profile/Anja_Lorenz/publication/263543544_Open_Online_ Courses_in_the_context_of_higher_education_an_evaluation_of_a_German_cMOOC/ links/54941c560cf2e1b6095f97bc/Open-Online-Courses-in-the-context-of-higher-educationan-evaluation-of-a-German-cMOOC.pdf\#page $=58$ 
Hall, E. T. (1976). Beyond culture. New York, NY: Anchor Press

Hannon, J., \& D’Netto, B. (2007). Cultural diversity online: Student engagement with learning technologies. International Journal of Educational Management, 21(5), 418-432. https://doi. org/10.1108/09513540710760192

Henderson, F. M. (1996). Open channel flow. NY: Macmillan.

Hofstede, G. (1983). The cultural relativity of organizational practices and theories. Journal of International Business Studies, 14(2), 75-89. Retrieved from https:/link.springer.com/content/ pdf/10.1057\%2Fpalgrave.jibs.8490867.pdf

Hofstede, G. (1986). Cultural differences in teaching and learning. International Journal of Intercultural Relations, 10, 301-320. https://doi.org/10.1016/0147-1767(86)90015-5

Hofstede, G. (2001). Culture's consequences: Comparing values, behaviors, institutions, and organizations across nations (2nd ed). Thousand Oaks, CA: Sage Publications.

Hofstede, G., \& Hofstede, G. J. (2005). Cultures and organizations: Software of the mind (2nd ed). New York, NY: McGraw-Hill.

Jagannathan, S. (2015). Harnessing the power of open learning to share global prosperity and eradicate poverty. In C. J Bonk, M. M. Lee, T. C. Reeves, \& T. H. Reynolds (Eds.), MOOCs and open education around the world (pp. 218-231). New York, NY: Routledge.

Jordan, K. (2013). MOOC completion rates: The data [Web log post]. Retrieved from http://www. katyjordan.com/MOOCproject.html

Jordan, K. (2014). Initial trends in enrolment and completion of massive open online courses. The International Review of Research in Open and Distributed Learning, 15(1), 133-160. Retrieved from http://www.irrodl.org/index.php/irrodl/article/view/1651/2774

Jung, I., \& C. N. Gunawardena, C. N. (Eds.) (2014). Culture and online learning: Global perspectives and research. Sterling, VA: Stylus Publishing.

Kahan, T., Soffer, T., \& Nachmias, R. (2017). Types of participant behavior in a massive open online course. The International Review of Research in Open and Distributed Learning, 18(6), 1-18. Retrieved from http://dx.doi.org/10.19173/irrodl.v18i6.3087

Kim, K. J., \& Bonk, C. J. (2002). Cross-cultural comparisons of online collaboration among pre-service teachers in Finland, Korea, and the United States. Journal of Computer-Mediated Communication, 8(1), http://onlinelibrary.wiley.com/enhanced/doi/10.1111/j.1083-6101.2002.tb00163.x/

Kim, P., \& Chung, C. (2015). Creating a temporary spontaneous mini-ecosystem through a MOOC. In C. J. Bonk, M. M. Lee, T. C. Reeves, \& T. H. Reynolds (Eds.), MOOCs and open education around the world (pp. 157-168). New York, NY: Routledge.

Kizilcec, R. F., Perez-Sanagustin, M., \& Maldonado, J. J. (2017). Self-regulated learning strategies predict learner behavior and goal attainment in massive open online courses. Computers \& Education, 104, 18-33. https://doi.org/10.1016/j.compedu.2016.10.001

Kondratova, I., Goldfarb, I., Gervais, R., \& Fournier, L. (2005). Culturally appropriate web interface design: Web crawler study. Proceedings of the 8th IASTED International Conference of Computer and Advanced Technology in Education (pp. 359-364). Retrieved from https://www.researchgate. net/profile/Irina_Kondratova/publication/44047947_Culturally_Appropriate_Web_Interface_ Design_Web_Crawler_Study/links/563cb54308ae405111aa4a50.pdf

Kop, R. (2011). The challenges to connectivist learning on open online networks: Learning experiences during a massive open online course. International Review of Research in Open and Distributed Learning, 12(3), 19-38. Retrieved from http://www.irrodl.org/index.php/irrodl/article/view/882/1689

Liu, Z., Brown, R., Lynch, C. F., Barnes, T., Baker, R., Bergner, Y., \& McNamara, D. (2016). MOOC learner behaviors by country and culture; an exploratory analysis. International Educational Data Mining Society. Retrieved from https://files.eric.ed.gov/fulltext/ED592695.pdf 
Mackness, J., Mak, S., \& Williams, R. (2010). The ideals and reality of participating in a MOOC. Proceedings of the Seventh International Conference on Networked Learning, University of Lancaster. Lancaster, MI. Retrieved from http://www.lancs.ac.uk/fss/organisations/netlc/past/nlc2010/abstracts/ Mackness.html

Markoff, J. (2011, August 15). Virtual and artificial, but 58,000 want a course. The New York Times. Retrieved from http://www.nytimes.com/2011/08/16/science/16stanford.html?_r=0

McAuley, A., Stewart, B., Siemens, G., \& Cormier, D. (2010). The MOOC model for digital practice. Unpublished manuscript, University of Prince Edward Island. Retrieved from www.elearnspace. org/Articles/MOOC_Final.pdf

McLoughlin, C. (2006). Inclusivity and alignment: Principles of pedagogy, task and assessment design for effective cross-cultural online learning. Distance Education, 22(1), 7-19. doi: $10.1080 / 0158791010220102$

Miller, H., \& Jay, J. (2015). Open educational resources and MOOCs: Examining the changing face of content delivery in higher education. Global Education Review, 2(3).

Milligan, C., \& Littlejohn, A. (2017). Why study on a MOOC? The motives of learners and professionals. The International Review of Research in Open and Distributed Learning, 18(2), 92-102. http:// dx.doi.org/10.19173/irrodl.v18i2.3033

MOOC @ Edinburgh 2013 - Report \#1 (2013). MOOC @ Edinburgh 2013 - Report \#1. University of Edinburgh, Edinburgh, Scotland. Retrieved from https://www.era.lib.ed.ac.uk/bitstream/ handle/1842/6683/Edinburgh_MOOCs_Report2013_no1.pdf?sequence=1\&isAllowed=y

Moore, M., \& Kearsley, G. (2005). Distance education: A systems view (2nd ed.). Belmont, CA: Thomson Wadsworth.

Morse, K. (2003). Does one size fit all? Asynchronous learning in a multicultural environment. Journal of Asynchronous Learning Networks, 7(1), 37-54. Retrieved from https://pdfs.semanticscholar.org/ eea5/06b9cd56b83aedc8e673fbc57a420181c040.pdf

Nkuyubwatsi, B. (2014). Cultural translation in massive open online courses (MOOCs). ELearning Papers, 37, pp. 49-59. Retrieved from: http://centaur.reading.ac.uk/38250/1/\#page=49

Ostashewski, N., \& Reid, D. (2012). Delivering a MOOC using a social networking site: The SMOOC design model. Proceedings of IADIS International Conference on Internet Technologies \& Society (pp. 217-220). Retrieved from http://hdl.handle.net/20.500.11937/28872

Pappano, L. (2012). The year of the MOOC. The New York Times, 2(12). Retrieved from http://www. nytimes.com/2012/11/04/education/edlife/massive-open-online-courses-are-multiplying-at-arapid-pace.html

Paquette, G., Mariño, O., Rogozan, D., \& Leonard, M. (2015). Competency-based personalization for massive online learning. Smart Learning Environments, 2(1), 1-19. https://doi.org/10.1186/ s40561-015-0013-z

Preece, J., Rogers, Y., \& Helen, S. (2007). Interaction design: Beyond human-computer interaction (2nd ed.). New Jersey: John Wiley \& Sons.

Rappert, B. (1999). Rationalising the future? Foresight in science and technology policy co-ordination. Futures, 31(6), 527-545. https://doi.org/10.1016/S0016-3287(99)00012-9

Reeves, T. C., \& Reeves, P. M. (Eds.). (1997). Effective dimensions of interactive learning on the World Wide Web. Englewood Cliffs: Educational Technology Publications.

Renner, D., Laumer, S., \& Weitzel, T. (2015). Blended learning success: Cultural and learning style impacts. Paper presented at 12th International Conference on Wirtschaftsinformatik, 4-6 March 2015 (pp. 1375-1390). Osnabruck, Germany. 
Riel, J., \& Lawless, K. A. (2017). Developments in MOOC technologies and participation since 2012: Changes since "The year of the MOOC." In M. Khosrow-Pour (Ed.), Encyclopedia of information science and technology (4th ed.), Hershey, PA: IGI Global, Forthcoming.

Rodriguez, O. C. (2012). MOOCs and the AI-Stanford like courses: Two successful and distinct course formats for massive open online courses. European Journal of Open, Distance and E-Learning, 1(2), 1-13. Retrieved from https://files.eric.ed.gov/fulltext/EJ982976.pdf

Rogers, P. C., Graham, C. R., \& Mayes, C. T. (2007). Cultural competence and instructional design: Exploration research into the delivery of online instruction cross-culturally. Educational Technology Research \& Development, 55(2), 197-217. doi: 10.1007/s11423-007-9033-x

Sandeen, C. (2013). Assessment's place in the new MOOC world. Research \& Practice in Assessment, 8, 5-12. Retrieved from https://files.eric.ed.gov/fulltext/EJ1062706.pdf

Schulze, A. S. (2014). Massive open online courses (MOOCs) and completion rates: Are self-directed adult learners the most successful at MOOCs? Retrieved from ProQuest Dissertations \& Theses Global.

Seufert, S. (2002). Cultural perspectives. In H. H. Adelsberger, J. M. Pawlowski \& B. Collis (Eds.), International handbook on information systems (pp. 411-421). Berlin, Germany: Springer.

Severance, C. (2015). Learning about MOOCs by talking to students. In C. J. Bonk, M. M. Lee, T. C. Reeves, \& T. H. Reynolds (Eds.), MOOCs and open education around the world (pp. 169-179). New York, NY: Routledge.

Shah, D. (2015, December 21). By the numbers: MOOCs in 2015. Class Central. https://www.class-central. com/report/moocs-2015-stats/

Shah, D. (2016, December 25). By the numbers: MOOCs in 2016. Class Central. https://www.class-central. com/report/mooc-stats-2016/

Shah, D. (2019, January 6). Year of MOOC-based degrees: A review of MOOC stats and trends in 2018. Class Central. https://www.class-central.com/report/moocs-stats-and-trends-2018/

Shishah, W., \& FitzGerald, E. (2016). Incorporating cultural factors into the design of technology to support teamwork in higher education. Proceedings of the 8th International Conference on Computer Supported Education (pp. 55-66). Rome, Italy.

Sieffert, S. (2006). Placing culture at the forefront. Educational Communications and Technology, University of Saskatchewan, Saskatoon, Canada. Retrieved from http://citeseerx.ist.psu.edu/viewdoc/ download?doi=10.1.1.493.249\&rep=rep1\&type $=$ pdf

Siemens, G. (2012a, January 19). Connectivist learning theory. Retrieved from the P2P Foundation Wiki. Retrieved from http://p2pfoundation.net/Connectivist_Learning_Theory___Siemens

Siemens, G. (2012b). Designing, developing, and running (massive) open online courses. Retrieved from https://www.slideshare.net/gsiemens/designing-and-running-a-mooc

Speece, M. (2012). Learning style, culture and delivery mode in online distance education. US-China Education Review, 1-12. Retrieved from https://files.eric.ed.gov/fulltext/ED530681.pdf

Subramony, D. P. (2004). Instructional technologists' inattention to issues of cultural diversity among learners. Educational Technology, 44(4), 19-24. Retrieved from https://www.jstor.org/ stable/44428919?seq=1\#metadata_info_tab_contents

Sunar A. S., Abdullah N. A., White S., \& Davis H. (2016) Personalisation in MOOCs: A critical literature review. In S. Zvacek, M. Restivo, J. Uhomoibhi, \& M. Helfert (Eds.), International Conference on Computer Supported Education (pp. 152-168). CSEDU 2015. Communications in Computer and Information Science, Vol 583. Springer, Cham. https://doi.org/10.1007/978-3-319-29585-5_9

Swierczek, F. W., \& Bechter, C. (2010). Cultural features of e-learning: A Euro-Asian case study. In J. M. Spector, D. Ifenthaler, \& P. Isaias (Eds.), Learning and instruction in the digital age (pp. 291-308). New York, NY: Springer. 
Teras, H. (2013). Dealing with "learning culture shock" in multicultural authentic e-learning. Proceedings of E-Learn 2013-World Conference on E-Learning in Corporate, Government, Healthcare, and Higher Education (pp.2988-2996). Chesapeake, United States: Association for the Advancement of Computing in Education (AACE). Retrieved from https://www.learntechlib.org/p/114878/

Tylor, E. B. (1871). Primitive culture. London: John Murray.

Veletsianos, G., \& Shepherdson, P. (2016). A systematic analysis and synthesis of the empirical MOOC literature published in 2013-2015. International Review of Research on Open and Distributed Learning, 17(2), Retrieved from http://www.irrodl.org/index.php/irrodl/article/view/2448/3655

Venkataraman, B., \& Kanwar, A. (2015). Changing the tune: MOOCs for human development? In C. J. Bonk, M. M. Lee., T. C. Reeves, \& T. H. Reynolds (Eds.), MOOCs and open education around the world (pp. 206-217). New York, NY: Routledge.

Wang, C. M., \& Reeves, T. C. (2007). The meaning of culture in online education: Implications for teaching, learning, and design. In A. Edmundson (Ed.), Globalized e-Learning Cultural Challenges (pp. 1-17). Hershey, PA: Idea Group, Inc.

Wang, M. (2007). Designing online courses that effectively engage learners from diverse cultural backgrounds. British Journal of Educational Technology, 38(2), 294-311. https://doi.org/10.1111/ j.1467-8535.2006.00626.x

Warugaba, C., Naughton, B., Gauthier, B. H., Muhirwa, E., \& Amoroso, C. L. (2016). Experience with a massive open online course in rural Rwanda. The International Review of Research in Open and Distributed Learning, 17(2), 222-231. Retrieved from http://www.irrodl.org/index.php/irrodl/ article/view/2401/3657

Watson, R. T., Ho, T. H., \& Raman, K. S. (1994). Culture: A fourth dimension of group support systems. Communications of the ACM, 37(10), 45-55. Retrieved from https:/go.galegroup. $\mathrm{com} / \mathrm{ps} / \mathrm{i} . \mathrm{do}$ ? $\mathrm{v}=2.1 \& \mathrm{it}=\mathrm{r} \& \mathrm{sw}=\mathrm{w} \& \mathrm{id}=\mathrm{GALE} \% 7 \mathrm{CA} 16385626 \& \mathrm{prodId}=\mathrm{AONE} \& \mathrm{sid}=$ google ScholarFullText\&userGroupName=ind23893_t tda

Wendler, M. C., \& Struthers, R. (2002). Bridging culture on-line: Strategies for teaching cultural sensitivity. Journal of Professional Nursing, 18(6), 320-327. https://doi.org/10.1053/jpnu.2002.129596

Yousef, A. M. F., Chatti, M. A., Schroeder, U., \& Wosnitza, M. (2014, July). What drives a successful MOOC? An empirical examination of criteria to assure design quality of MOOCs. Proceedings of 2014 IEEE 14th International Conference on Advanced Learning Technologies (pp. 44-48). IEEE. doi: 10.1109/ICALT.2014.23

Zhang, K., Bonk, C. J., Reeves, T. C., \& Reynolds, T. H. (Eds.). (2020). MOOCs and open education in the Global South: Challenges, successes, and opportunities. NY: Routledge. DOI: https://doi. org/10.4324/9780429398919

Zhu, M., Bonk, C. J., \& Sari, A. (2019). MOOC instructor motivations, innovations, and designs: Surveys, interviews, and course reviews. Canadian Journal of Learning and Technology, 45(1), 1-22. doi: https://doi.org/10.21432/cjlt27795

Zhu, M., Sari, A., \& Lee, M. M. (2018). A systematic review of research methods and topics of the empirical MOOC literature (2014-2016). The Internet and Higher Education, 37, 31-39. https://doi. org/10.1016/j.iheduc.2018.01.002 